\title{
From Rural Poverty to Urban Deprivation? The Plight of Chinese Rural-Urban Migrants Through the Lens of Last Train Home
}

\author{
Na Li • Wei-Hsin Lin • Xiaobing Wang
}

Received: 28 June 2011 / Accepted: 8 February 2012 / Published online: 3 March 2012

(C) Springer Science+Business Media B.V. 2012

\begin{abstract}
China's impressive growth has been accompanied by huge rural-urban divide and social sacrifice of many including rural-urban migrants. Reflecting on the documentary Last Train Home (2009) by Lixin Fan, this paper identifies and examines the life of rural-urban migrants in China in terms of poverty-reduction, child-care, education and equal opportunities for a better life. By comparing the seemingly difficult and tragic life of the Zhang family against statistical facts, it shows that their suffering and struggles are common to most migrants. In essence, by creating an interactive dialogue between the film and the economic reality in China, this paper highlights the severe constraints on the Chinese peasantry and discusses the implications of limited choices and social injustice towards rural-urban migrants. It argues that the inequality in opportunities and the lack of social care for migrants has created huge social cleavage that not only reduces social welfare but may also impede further development.
\end{abstract}

Keywords China $\cdot$ Hukou system $\cdot$ Last train home $\cdot$ Migrant workers $\cdot$ Urban-rural divide

\section{Introduction}

During the past 30 years, China has witnessed significant economic growth with a profound structural transformation from agriculture to industry. As part of this process, the country has experienced the largest labour migration in history. According to National Bureau of Statistics [11], at the end of 2008, China had 225 million migrant workers, that accounts for around one third of the total number of employed

\footnotetext{
N. Li $\cdot$ W.-H. Lin

Centre for Chinese Studies, The University of Manchester, Oxford Road, Manchester M13 9PL, UK

X. Wang $(\bowtie)$

Economics, School of Social Sciences and Centre for Chinese Studies, The University of Manchester, Oxford Road, Manchester M13 9PL, UK

e-mail: Xiaobing.Wang@manchester.ac.uk
} 
persons in China. The number of migrant workers who work outside of their hometowns totalled 140.41 million, more than 60 per cent of total migrant workers.

As China's economic growth is largely supported by labour-intensive manufacturing industries and labour is a crucial factor of production in this growth, it is necessary to achieve a better understanding of the welfare status of migrant workers.

There have been extensive studies of the magnitude and dimensions of the ruralurban divide from an economic point of view (for example, $[9,10]$ ) and many studies of aspects of the hardship of rural-urban migrants from a sociological and anthropological point of view [7, 21]. There have also been many newspaper reports and TV documentaries about the lives of Chinese migrants. However, there are very few films investigating the world of Chinese rural-urban migrant workers.

A recent documentary film, Last Train Home by Lixin Fan, allows us to look into the lives of a typical migrant family, the Zhang family, their struggle for money and a better life. The film provides a rare opportunity for systematic study of the widening ruralurban divide and the consequences of macroeconomic policies in ordinary people's lives.

The Zhang family was trapped in poverty back in the 1990s, when the couple, Changhua Zhang and Suqin Chen had to borrow 50 Yuan to go to hospital for the birth of their daughter Qin Zhang. They migrated in the hope of escaping poverty. However, working in a factory in Guangdong province, about 2000 kilometres away from their hometown in Sichuan province, meant they had to leave their children at home with their aging and frail parents, and were only able to come home and stay for two weeks with their children and parents once a year.

Since its release, Last Train Home, has attracted a great deal of publicity and won the director critical acclaim. However, so far there has not been an academic study exploring this film from the perspective of China's economic policies and their impact on migrants' lives. Almost all the published articles that set out to analyse this film are movie reviews which focus either on the grim reality the Zhang family are confronted with or on the cinematography of the film. For example, New York Times' film critic, A.O. Scott [15], praises the film for its depiction of the "almost unbearably harsh conditions" of China's migrant workers, while Roger Elbert [2] notes how difficult it is for the huge population of China's poor rural citizens to "rise from poverty." Nonetheless, none of them mention the relevant economic policies to which could be attributed the plight China's migrant workers suffer. On the one hand, professional film critics' accolades of Last Train Home confirm for us the huge impact its portrayal of Chinese migrant workers has on people outside academia, people who do not necessarily have much knowledge of contemporary China but feel deep empathy for migrant workers as they witness the social and domestic conflicts which rack and tear apart the Zhang family. On the other, these reviews unanimously end with reference to the melancholy tone the director sets for this film. Tragedies and conflicts have been unfolded, but a deeper reasoning and analysis of the causes are lacking. As the significance of Last Train Home has been recognised in terms of its vivid portrayal of the social turmoil incurred by the problems of domestic migration, a more rigorous study of the film and the issues this film addresses is urgently needed.

In addition, while the film and many of the studies make a vivid presentation of the personal experience of struggle for a meaning in life, there is a need for a macro economic analysis that highlights the importance and the impact of the macroeconomic environment on unprivileged migrant workers. 
This paper first systematically investigates and reviews the multiple dimensions of hardship for rural-urban migrants. ${ }^{1}$ By linking our analyses of each dimension to the scenes in the documentary film, Last Train Home, this paper tries to bridge the gap between formal academic study and appreciation of the film to enhance our understanding of the issue. Second, by study the social discourse and the multidimensional deprivation together with special references to scenes in the film, we identify and investigate the reasons behind the plight of Chinese rural residents and rural-urban migrants and study the possible causes, bridging the gaps in our knowledge. Our emphasis is on the macroeconomic environment of those migrant workers. It is very easy for one to blame these migrants as selfish or materialist. Without knowledge of their hostile environment it is impossible to understand that many of their seemingly irrational choices and hardships are consequences of a macro reality over which they have no control.

In essence, through the lens of Last Train Home, this paper studies how the lives of migrant workers are affected by the macro policies that they cannot control. It unveils a mechanism that traps them in a disadvantageous position that despite all their strenuous efforts they cannot escape, as well as the price they have to pay by leaving their children behind.

The rest of this paper is organised as follows. Rural Poverty and Barriers to Migration examines China's economic policies concerning the welfare of rural peasants and rural-urban migrant workers; Migrant's Unpalatable Choice of Child Care investigates the unpalatable choice of child care for migrant workers; Mounting Pressure but Little Support in Education studies migrants' dilemma and helplessness in educating their children; followed by a demonstration of how little migrant workers benefit despite their tremendous contribution to the economy in Fuel the Growth but not Reap the Benefits. Conclusion concludes with some policy implications.

\section{Rural Poverty and Barriers to Migration}

Since the start of the reforms in 1978, China's real GDP has been growing at an average of around 10 per cent per annum, 200 million people have been lifted out of "extreme poverty," according to National Bureau of Statistics [11]. This impressive growth in national income has, however, been accompanied by increasing income inequality and rural-urban divide. In 2009, there were still around 150 million people in China, almost exclusively in rural areas, living on less than US\$1 a day in purchase power parity. They account for around 18 per cent of the world's extremely poor [11]. For these destitute rural dwellers, avoiding dire living conditions becomes a strong incentive to migrate to big cities, an incentive which is, however, thwarted by China's Hukou system.

\section{China's Hukou System}

One distinctive policy in China is the Household Registration (Hukou) system. Introduced in the 1950s, the Hukou system is a de-facto internal passport mechanism

\footnotetext{
${ }^{1}$ However, this paper does not intend to make a detailed review of the large literature on rural poverty and rural-urban migration in China.
} 
preventing unauthorized movement between sectors. It created invisible walls and administrative barriers that divided China into two worlds: those who live in the urban sector enjoy many rights and privileges while those in rural areas have far fewer political rights or opportunities to participate in or influence policies that will affect them [9, 19].

The Hukou system contributed to different levels of development in urban and rural areas and severely reduced the extent to which rural people can migrate to urban areas for a higher income and a better livelihood. NBS [12] shows that average urban household income is continuously around three times as high as the income of the average household in rural areas. This rural-urban income gap is among the widest in the world [14]. Since the reforms began, although there has been a continual loosening of controls and restrictions on rural labour moving to cities, it still remains extremely difficult for a rural person or household to become a permanent urban dweller, to obtain an urban Hukou.

According to NBS [11], there were about 140 million migrants living and working in urban areas but not able to get urban Hukou and thus settle in cities. ${ }^{2}$ These migrants do not enjoy the same rights as many local residents do and only work as casual workers on a temporary basis. So they are given the appellation: the "floating population," as they are rooted neither in the country nor in big cities. The Hukou system makes them drift between rural and urban areas while it also seriously segments China's labour markets.

\section{Segmented Labour Markets}

The labour market in China has been highly segmented with migrant workers suffering unfair discrimination. [10, 18]. Apart from a big income gap, the urban and rural dwellers also face a big employment gap.

Having surplus labour is one of the social phenomena of China and the rural areas have operated as the sink of this surplus labour. The result is that urban areas enjoy an average income based on institutional wages that are substantially higher than the average rural income based on a subsistence level [10]. The fragile position of rural workers is further compounded by the fact that they lack alternative opportunities, information about alternatives and social security.

The agriculture sector in general has high levels of surplus labour and very low marginal productivity. The route out of this adverse circumstance is migration to the urban sector. Rural people are aware that better remuneration for their labour exists outside agriculture but, without good education or necessary training, they have limited opportunities to pursue non-agricultural activities. On top of these, the Hukou system makes it even more difficult to migrate.

At the beginning of the reform, rural residents needed a permit to allow them to migrate to other areas in order to work and these were issued on a quota basis. On arrival in a new city, they were required to register with the police, and both the permit and registration were subject to a fee. These fees were often very high, posing an insurmountable barrier for some rural citizens and a deterrent for many [18].

\footnotetext{
${ }^{2}$ Zhang's family is one of them.
} 
Moreover, there are limited employment opportunities for rural migrants as a result of city governments' attempts to minimise unemployment for urban residents in order to maintain social order [10:184]. For example, in the 1990s, State Owned Enterprises (SOEs) were required to give jobs to urban residents first and to employ a certain proportion of local residents despite the fact the migrants would have been prepared to work for a lower wage. In fact, the political and institutional arrangements give urban residents privileged access to secure employment at above market-clearing wages and controlled the flow of peasants to the cities, allowing rural migrants to fill only the vacancies that urban-dwellers did not want.

Past research has shown that labour markets in China have been highly segmented for many years [9]; Appleton et al, 2004; [10]. Despite the recent relaxation in regulations, barriers in the form of government restrictions on labour movement remain. Job-opportunities for labour are much greater in urban areas, where only between 3.6 and 4.3 per cent were registered unemployed from 2000 to 2005 (NBS). In contrast, the number of surplus labourers was still around 50 per cent in rural areas in the same period according to the estimate of Kwan [8]. As Zhang [21, 22] shows, most migrants can only get unskilled jobs. They work longer hours, are not entitled to or able to afford to participate in the welfare system, such as medical insurance and pension schemes. Unemployed people with urban Hukou can claim minimum income subsidies and enjoy pensions and unemployment insurance. However, the situation is different for those with rural Hukou, for whom none of these security nets have existed until very recently.

Despite the seemingly harsh conditions, many migrants do not want to go back to the countryside nor to become farmers again [21]. All these inequalities Chinese migrant workers have to live with when they choose to move to big cities which counter balance the aspiration to escape destitution in the countryside explain the background of the dilemma for a typical migrant family. The Zhang family in the film is such an example.

\section{Migrant's Unpalatable Choice of Child Care}

The relationship between the migrant workers and their children is the focus of attention and the flashpoint of conflicts in this film, which also illustrates the negative impact of migration to urban sectors for migrant families. When migrant workers have children, they face an unpalatable choice of child care: whether they want to take children with them to the urban areas, or leave them at home in the rural areas. This section discusses the difficulties the migrants face concerning how to look after and interact with the children that either move to cities or are left behind.

Take Children with them in Urban Areas

When children come and live with migrant workers in cities, there is not often any properly devised child care available to them. The film gives us a vision of how very young children are often left unattended to play on busy roads or play and sleep in factories packed full of materials which pose great hazard to them. This is mostly due to the fact that there is either no proper child care system available to migrants or nothing 
affordable to migrant workers even when the facilities do exist. According to the AllChina Women's Federation [1], ${ }^{3}$ the equivalent to a Ministry for Women, there are 19 million migrant children living with their parents in the cities, in the adverse conditions which, as shown in the film, accentuate their status as second-class citizens.

Although under the constitution Chinese children are entitled to a state free education, the reality is that millions of migrants' children cannot be enrolled into the schools in the cities they work and live because they do not have urban Hukou there. Instead, many of these children have to attend private schools that run on fees, donations and voluntary teachers. These schools often have poor infrastructure and provide education of low quality which results in disappointing academic performance compared to that of city children.

\section{Leave Children Back Home in Rural Areas}

Aware of the difficulties of child rearing in urban areas, many migrant workers leave their children at home in the rural areas. This has, however, created another phenomenon known as the "left-behind children" problem (liushou ertong), where one or both of the parents work far from home and leave the children in the care of grandparents, other relatives, or alone. The causes of this situation include the fact that migrants themselves see their move as temporary - their rural Hukou status is fixed and they may have to return to the country-side if they become unemployed. In addition, low wages and high cost of living in urban areas means that it is too expensive to have their children stay with them. Finally, the Hukou restrictions make it difficult for the children of migrant workers to attend schools in the urban areas.

Geographic barriers and economic barriers-the ticket price and the time they can afford not working are thus translated into an emotional barrier. Parents can only afford to come home and spend time with family for a couple of days in the year. The emotional barriers make it difficult for parents and children to communicate and they end up with very weak emotional ties, especially with young children.

By 2008, China had 140 million rural workers working away from their home towns [11], creating a large number of left-behind children. The All-China Women's Federation [1] estimated that there were about 58 million "left-behind children" aged up to 17 and about 40 million left-behind children under 14 . Roughly 28 per cent of all children living in the countryside are "left behind." Among these "left-behind children", nearly 53 per cent have both parents working away and among these, 48 per cent of them live with their grandparents. A problem with this arrangement is that the adults taking care of these children do not receive good schooling and thus they often only cater for children's basic needs but are incapable of providing educational or emotional support. It is not unusual that since these children are left alone for much of the time, there are frequent reports of child suicides and criminal activities that are attributable to negligence and lack of appropriate care [1].

\footnotetext{
3 The All-China Women's Federation (ACWF) is a mass organization dedicated to the advancement of Chinese women of all ethnic groups in all walks of life. The basic functions of the federation are to represent and safeguard the rights and interests of women and promote equality between men and women. ACWF has a Department of Children (because Children were considered as a main factor in women's welfare), who frequently conduct research concerning rural left-behind Children.
} 
This typical life is convincingly shown in the film. The two children in the film, Qin Zhang and Yang Zhang are among the children that had been "left-behind." As their parents, Changhua and Suqin, were not able to afford to come home more often or stay more than two weeks a year, their connection with the children is established mainly by short conversations over the phone. As a result, the emotional link between parents and children becomes very tenuous. Originally, Qin and Yang live with their grandparents but, after the death of the grandfather, the aging grandmother becomes the only senior family member Qin and Yang feel emotionally bonded to. However, as stated earlier, the poor education of the grandmother means she is unable to help the children with their study, relieve the stress they are put under at school or assuage the loneliness they feel for being virtually abandoned in the countryside. Throughout the film, the audience is constantly presented with her views when she keeps reiterating the Confucian doctrines of the importance of filial piety and academic achievement.

Besides this ongoing sermonising, we can see that Qin and Yang are burdened with further agricultural work to help their grandmother after school. Even so, the audience can still sense that the relationship they have with their grandparents is much stronger than that with their parents. This is further illuminated when Qin, after deciding to leave her hometown to work in the big city, goes down on her knees and sobs bitterly in front of her grandfather's tomb, as a way of bidding farewell. When her parents come home for Chinese New Year and the mother states her intention of staying with them, Qin scorns her declaration by assuring her brother that she is not serious about it because she only cares about the money she can make in the city. . The stark contrast between Qin's affection for her grandparents and her parents foreshadows the irrevocable break down (one word) of this parent-child relationship.

\section{Mounting Pressure but Little Support in Education}

The gap between urban and rural education manifests itself through many aspects, including cost, level, quality and returns on education $[6,16]$. Schools in urban areas receive a large amount of support from the government while those in rural areas get strikingly little. ${ }^{4}$ Rural residents are also required to contribute via taxation to the maintenance of the physical infrastructure of schools and the teachers' salaries [5, 20]. Many rural areas are so deprived that tax revenue is insufficient to pay for schools, and where they do exist, the schooling is of low quality [16,20], not to mention that some families are not even able to send their children to school because they can not afford the tuition fees. ${ }^{5}$

In China, the second most important factor influencing a person's educational attainment or enrolment, after age, is whether that person lives in a rural or urban area [9]. In 2005, the percentage of senior-high school graduates from urban areas was three times higher than that from rural areas and the percentage of college graduates

\footnotetext{
${ }^{4}$ It is noted that educational expenditure is dependent on rural households' income [17], and the lack of sufficient finance has led to a decline of the provision of education for many rural citizens [20].

${ }^{5}$ It should be noted that rural agriculture tax and fees were abolished in 2006 and tuition fees have been gradually reduced (or abolished in some areas) since 2008. However there may still be incidental costs to attendance at school which may be important.
} 
was four times higher (NBS). It has been estimated that if rural education levels were to increase to those of urban areas, the overall rural-urban income gap would be narrowed by 25-30 per cent [14].

It should be noted that returns on education in China have been found to be low when compared with other countries, but this is especially the case in rural areas [18]. Low returns on education particularly in rural areas and especially for high schools means that there is little incentive for families to pay for their children's education. All these factors amalgamate to trap many rural people in perpetual inequality where poor education destines them for taxing jobs with low wages.

In essence, rural Hukou people are seriously discriminated against by the government's education policies. In rural areas, there is always a lack of human and financial resources for better education, while in urban areas, migrant children face institutional discrimination due to their Hukou status. As a result, in general, those who are leftbehind and those who move to cities with their parents are both noted for their poorer academic performance and behavioural problems in comparison with their urban peers.

The hardship the migrant workers endure makes them entertain the hope that one day their children could enter university and break from the vicious cycle of low professional knowledge or skill and low-paid jobs. This is vividly shown from the words the grandmother utters when doing her house chores: "if they want to leave the countryside, they have to study hard." so it is not surprising when Changhua and Suqin try to persuade Qin to go back to school after she drops out by admonishing her: "you should not be like us. You should go back to school!" Every time they get a chance to talk with their children, the phrase "study hard" is reiterated stubbornly. It transfers to the mounting pressure that is sometimes too much for these children to withstand. To blame the children for not studying hard enough or doing well at school is a convenient outlet for the parents' disappointment, especially if they are unaware of the detriment caused their offspring by lack of support from parents and the huge pedagogical gap between rural and urban areas. Children themselves are often the victims of the education system in China but they are usually blamed for not achieving much academically by people who are not aware of the abject educational resources in the country.

Hence, while education is regarded by many migrant workers as the only avenue to a life not clouded by poverty, there is certainly a huge chasm between the parents' perception of how their children can benefit from education and what these children actually experience at school. This kind of chasm also contributes to the misunderstanding and rift between Suqin and her children in the film. As Suqin indicates near the end of the film, there is no healthcare service, unemployment insurance or pension scheme devised for migrant workers like them. One way of dealing with this lack of sound welfare system is to accumulate some precautionary savings but the attempt to save some money by Changhua and Suqin is seen by many, including their daughter Qin, as greedy and obsessive about money. While it is difficult for Qin, a teenage girl now at the age of being rebellious, to conceive the dire working conditions her parents have to bear, the fact that the burden of farm work falls on the grandmother and two young children merely makes her more resentful. Suqin never stops reciting her aspiration for a better education for her children as the only way of pulling them out of poverty. While having dinner with Qin and her younger 
brother, the grandmother also admonishes them to study hard with the expectation that, once they get better jobs and achieve success, the whole family can benefit from it materially and thus live a less harsh life. Consequently, even though the older generation tends to use material comfort as an incentive to galvanise their children into study, the younger ones, nonetheless, are too besieged by pressure, loneliness and resentment against their parents to see what Changhua, Suqin, and the grandmother really expect from them. In the end, education does not become the lifesaver that salvages the migrant workers and their families from penury, but aggravates the collision between two generations.

An even gloomier fact is that many migrant children would simply choose to interrupt or even withdraw from their studies, the path Qin and many of her classmates follow. It seems inevitable when we consider the fact that these children need to withstand the huge pressure their parents and the society put them under in the hope that they can outperform others at school, without much help academically and emotionally from anyone, coupled with the gruelling farm work they have to do at the end of a day's classes.

When their daughter drops out of school, Changhua and Suqin's hopes seem to fade. As they do not want the same story to repeat itself in their son, Suqin is considering moving back to the countryside to take care of him. However, this does not promise a rosier future either. Not only is there little she can do in terms of helping with his study, but she may also build up further pressure with high expectations for his performance. With their daughter following in their footsteps to become another migrant worker and the remote possibility of helping their son with his learning which they hope can lift them into a more comfortable life, Changhua and Suqin, and their children are very likely to end up being trapped in the vicious cycle that enmeshes millions of migrant workers.

\section{Fuel the Growth but not Reap the Benefits}

As the film director, Lixin Fan, puts it, migrant workers "have contributed the most to China's prosperity but benefited the least" $[3,4]$. This statement is attested by the fact that rural migrant workers are not able to gain an urban Hukou or the right to stay in urban areas as permanent residents even though they might have worked there for decades, which is exactly what happens to the Zhang couple in the documentary who have been working in the city for 16 years but are still not granted an urban Hukou and the right to settle in urban areas. Consequently, they are not allowed to enjoy the same healthcare, education and social services as their urban counterparts. Were they to have migrated to another country and worked there for the same period of time they would have been eligible for full citizenship. ${ }^{6}$ The problematic social policies are detrimental to the children of the migrant workers who cannot obtain urban Hukou either since Hukou is inherited. Therefore, when Qin decides to work in the city too, like her parents, she can only be one of the casual labours, blocked from the

\footnotetext{
${ }^{6}$ The UK, for example, has allowed permanent residency to be gained after legally working for 5 years, or lawful residence for 10 years. A full citizenship may be granted one year after the grant of permanent residency.
} 
privileges only available for people with urban Hukou. The presence of the "second generation migrants" clearly demonstrates the depth of discrimination against rural dwellers in China. Many migrant workers are thus faced with a serious dilemma: they are neither willing to return to the countryside because of the lower income nor are they able to settle in the cities because of Hukou restrictions. The situation becomes even trickier for the young migrant workers who grow up in urban areas, have no knowledge of farming and want to live an urban life.

To be denied urban Hukou causes another huge problem for the migrant workers, the largest annual human migration that takes place every Chinese New Year. As pointed out earlier in the article, many migrant workers can only afford to travel back home once a year to be reunited with their family, and most of them choose to embark on this journey during the Chinese New Year holiday. The large number of migrant workers and the considerable distance between coastal cities and their remote hometowns mean this journey is an incredibly arduous one. They have to be crammed into trains and coaches for days, enduring stifling air and unsanitary public toilets before finally arriving home. When the transport goes wrong, all the problems are severely aggravated. As the film shows, in 2008, the heavy snowfall in many cities in China caused massive disruption to traffic, and left a vast sea of passengers stranded in the railway stations for days. The Zhang family did not avert this disaster. They stayed in the station for five days before finally getting tickets, while others waited even longer and eventually had to give up.

While the limited capacity of the rail system is partly to blame, the root cause for this pandemonium is the Hukou system and China's industrial development policies. ${ }^{7}$ The special economic zones that enjoyed tax and policy advantages were almost all in the coastal areas. These policies that favoured the coastal areas magnified the geographic disadvantages of inland regions. The uneven development means people have to travel thousands of kilometres away from home to find work opportunities. Only about ten years ago, China started the so called "Developing the West" movement but this has been limited to words as neither the investment and policy treatment by the central government is moving in favour of the West regions. This regional segmentation has compounded the vertical segmentation by the Hukou system in the Chinese society.

The Hukou system means the migrant workers don't have a home in cities, and they cannot settle in the place where they work. Chinese New Year is the only time in a year when they can get together with the family they are distanced from geographically and emotionally, and try to consolidate the family values most of them cherish, as demonstrated by one of the passengers on the same train with the Zhang family: "If the family cannot even spend the New Year together, life would be pointless."

Nevertheless, to reunite with one's family does not mean to repair effectively the broken relationship between Changhua, Suqin and their children. When we examine their interactions, it is evident that the affection the children should feel is reified by

\footnotetext{
${ }^{7}$ In one of the scenes in the film, a frustrated man shows his anger towards a soldier who is enforcing law and order in the railway station. He is angry that the soldier stopped him but what really separates him are the barriers he cannot see. They are imprisoned by the macro policies that are invisible and much more difficult to escape. It is those invisible institutional barriers, not the physical barriers before them leave them in frustration.
} 
the amount of money the parents send home and by the marks on their exam papers, the marks that are considered conducive to a better life brought forth by better jobs and higher incomes. While Qin and her brother are acutely aware of the weight money plays in their relationship with their parents, the older generation involuntarily draws a parallel between the younger generation's achievement and material affluence. It is therefore predicable that they are inclined to show their affection towards their children in the form of their stressful concerns about the marks they get and their ranking among their classmates. The alienation between the parents and their offspring climaxes in the verbal and physical row between Changhua and Qin, the father and the daughter. When she can no longer restrain her temper and swallow his reprimand, she flares up and hurls a swear word, incurring the outburst of his rage and the hard blows from both sides. The purpose of making this gruelling journey home to be reunited with their family seems wrong. At the end of the film, seeing their relationship turn irretrievably sour, Changhua and Suqing can only let their estranged daughter have her way.

When Qin was asked "is life good?" away from the countryside, she answers "to me, freedom is happiness". However, the fundamental question that remains unanswered is "free of what?" At the individual level, Qin gets away from family controls, has some personal income, can do the things she wants to do, away from an environment that is always telling her to study hard. However, what she and many other young migrants cannot escape is the macroeconomic environment that they cannot control. It is estimated that more than half of the inequality of income in China is caused by inequality of opportunity [23]. These are factors over which individuals have no influence, factors like family background, region of birth and gender, and are different from individual choices such as individual efforts or type of work [13]. This high degree of inequality of opportunity is partly due to the Hukou system which has allowed economic advantage or disadvantage to be transmitted from one generation to the next, thus making it very difficult to escape the poverty trap.

In the final scene of the film, we see Qin put on a quite revealing dress and high heels to wait on customers in a rackety nightclub. She escapes from the backwater of China to, as she declares in front of the camera, "pursue her dreams," and she plunges into a world which seems to epitomise the decadence of capitalism. If one day she gets tired of working in such a hazardous place, without professional knowledge or skills, she can only shift to work in a laborious but low-paid job just as her parents do. Whatever she dreams to do, to end up being like her parents is unlikely to be one of the achievements she wants to boast of. However, this is to a large degree what the future holds for the majority of Chinese migrant workers. Without the amelioration of relevant policies and systems, the same kind of life is very likely to be repeated from one generation to another. ${ }^{8}$

\footnotetext{
${ }^{8}$ It should be noted that there have also been some improvements at the macro level in the past few years. Since 2008, the central government has started to introduce a basic health care (new rural co-operative medical scheme, which covers 40 per cent of cost for in-patient) and a basic pension scheme for all rural residents. A recent small scale field study in Shaanxi province conducted by the authors in 2011 shows, that the abolition of agricultural tax, subsidies in rural education, the introduction of basic healthcare and a pension scheme, along with the increase in wages, has given rural residents and migrants a sense of improvement and appreciation.
} 


\section{Conclusions}

Last Train Home demonstrates to the audience the fear of being left behind in the impoverished and shrivelled countryside which instigates a vast number of rural dwellers to migrate to cities. It also confronts the audience with the miserable working conditions, the strained parent-child relationships and unpromising future the migrant workers have to face. Most important of all, it portrays contemporary China as a country dashing towards modernity while casting away its traditional ways of life. The dichotomy between modernity and tradition is illustrated by different lifestyles in urban and rural China, as well as by different attitudes towards life between two generations. China's journey to development costs its citizens dear, exposed not only by different standards of living in rural and urban areas and by damaged familial relationships, but also by the psychological transformation of people's attitudes towards life and happiness.

On a larger scale, the film urges us to re-examine the social fabric and the psychological wounds caused by China's economic boom and to ponder the possibility of repairing and curing them with the correct economic and welfare policies. It raises our expectations for changes that could be brought about by abolishing the Hukou system and improving social welfare. Once the flaws in China's internal policies have been exposed and investigated, possible solutions to social injustice can also be suggested.

There have been many micro level studies from an economics, sociology and anthropology point of view, but the macro picture is less researched. There is a major gap in the literature that needs to be addressed. That is the theoretical issues related to mechanisms that entrap rural residents and rural-urban migrants; the invisible net that they have very little control of, however hard they try. In addition, this paper provides a systematic and comprehensive analysis on the issues that the Zhang family and other migrants face, and serves as a bridge between popular culture and academe by connecting economics with film study, which shows another possible way of interpreting films.

It connects the life of an individual family shown in the film with millions of other migrants, connecting the film with reality in China. It studies the rural-urban divide and the related social issues and the economic and social policies that pertain to this phenomenon. The Hukou system which has been implemented to the detriment of the migrant workers for a long time has posed serious problems such as the widening difference between rural and urban life, the difficulty migrant workers experience settling down in cities, the lack of access to facilities and welfare for those who migrate from the country to live in cities, the "left-behind children," the broken parent-child relationships and the family bond that has thus been ruptured. Migrant workers have fuelled the country's spectacular growth but not reaped much of the benefit. This social injustice is too gross to be ignored.

With the number of migrant workers growing, a more worrisome sign is not only the current plight of migrant workers, but the macroeconomic environment that traps them in despair. For example, for many migrant workers, their dream is that their children may enter university, which promises a better job, a higher income and thus pulls them out of the rut of an unskilled and badly-paid job. However, given the poor educational infrastructure and the lack of support in rural areas, the prospect of the 
realization of this dream is slim. As a result, even if migrant workers are able to escape absolute poverty, it is very difficult for them and their families to rise from the lower echelon of society. The current limited social mobility is caused by the very small investment the government makes in education for migrant children. Thus, while well-educated people can usually occupy dominant social positions and gain more political or economic leverage, the possibility for migrant children to earn wages any higher than their parents' is faint and even less likely is it that they can climb up the social ladder.

As there are still more than 60 per cent of China's 1.3 billion population who are rural Hukou residents and with about 140 million migrant workers working in cities on a casual basis every year [11], there is a long way to go for China to be evenly urbanized. The only sustainable solution is systematic reform of the social welfare system and abolition of the Hukou system. This would have to be carried out gradually to avoid urban slums and social unrest. On the other hand, fairer distribution of budget and resources to urban and rural areas must be ensured in order to allow the countryside to thrive at a pace equal to big cities and to stem the largest human migration that takes place each year in China.

Acknowledgement The authors would like to thank the editor of this journal, the two anonymous referees, James St. Andre, Jenifer Piesse, Nicholas Weaver and Yangwen Zheng for useful comments and suggestions, Shuge Wang for her help with some of the data collection. Xiaobing Wang thanks the Centre for Chinese Studies Research Fund for financial support.

\section{References}

1. All-China Women's Federation (2008) "Quanguo nongcui liushou ertong zhuangkuang yanjiu baogao" (Research report on Chinese rural left-behind children). Beijing: Xinhua News Agency, February 27 th.

2. Ebert, Roger (2010) "Last Train Home", http://rogerebert.suntimes.com/apps/pbcs.dll/article?AID=/ 20101013/REVIEWS/101019988

3. Fan, Li Xin (2009) Last Train Home. Eyes Steel Film.

4. Fan, Li Xin (2009) “A Statement and Q \&A With Lixin Fan”, http://www.spiritualityandpractice.com/ films/features.php?id=20163

5. Hannum, Emily., (1999) "Political change and the urban-rural gap in basic education in China, 19491990”. Comparative Education Review, 43 (2): 193-211.

6. Hannum, Emily, and Albert Park (eds), (2007) Education and Reform in China, London: Routledge.

7. Jacka, Tamara., (2005) Rural Women in Urban China: Gender, Migration, and Social Change. Armonk, NY: M. E. Sharpe

8. Kwan, Fung., (2009) "Agricultural Labour and the Incidence of Surplus Labour: Experience from China During Reform”, Journal of Chinese Economic and Business Studies, 7 (3), 341 - 361.

9. Knight, John. and Lina Song, (1999) The Rural-Urban Divide: Economic Disparities and Interactions in China. Oxford: Oxford University Press.

10. Knight, John. and Lina Song, (2005) Towards a Labour Market in China. New York: Oxford University Press.

11. National Bureau of Statistics of China (NBS) (2009) "Statistical Communiqué on Labor and Social Security Development in 2008." May $22^{\text {nd }} \mathrm{http}: / / w w w . s t a t s . g o v . c n / e n g l i s h / n e w s a n d c o m i n g e v e n t s /$ t20090522_402560900.htm

12. NBS, (eds.) various years, China Statistic Yearbook, Beijing: China Statistics Press.

13. Roemer, J. (1998) Equality of Opportunity. Cambridge, Ma: Harvard University Press.

14. Sicular, Terry, Ximing Yue, Björn Gustaffson and Shi Li, (2007) "The Urban-Rural Income Gap and Inequality in China", Review of Income and Wealth 53 (1): 93-126. 
15. Scott, A.O., (2010) "A Family Caught in the Wheels of China's Industrial Locomotive", New York Times, September $2^{\text {nd }}$. http://movies.nytimes.com/2010/09/03/movies/03last.html

16. Tsang, Mun. (2000) "Education and national development in China since 1949: Oscillating policies and enduring dilemmas", China Review, 579-618

17. Wang, Hua-shu and Henk Moll, (2010) "Education Financing of Rural Households in China" Journal of Family Economic Issues. 31(3): 353-360.

18. Wang, Xiaobing and Jenifer Piesse,(2008) "Labour Market Segregation and Integration in China: A Spatial and Sectoral Analysis, 1988-2002" ("Whither Chinese Labour Market: A Study of Wage Structure Evolution in China") KCL Department of Management Research Paper Series No 51.

19. Wang, Xiaobing and Jenifer Piesse, (2010) "Inequality and the Urban-rural Divide in China: Effects of Regressive Taxation”, China and World Economy. 18(6): 36-55.

20. Yoxall, Jim., (2006) "Conflicts Surrounding Rural Education Reforms in China", Virginia Review of Asian Studies, 4: 1-21

21. Zhang, Mei., (2003) China's Poor Regions - Rural-urban Migration, Poverty, Economic Reform and Urbanization. London: Routledge Curzon

22. Zhang, Mei., (2010) "The Impact of Rural-urban Migration: Case study on the Loess Plateau of Central China”, China Information, 24(2): 169-189.

23. Zhang, Yingqiang and Tor Erikisson, (2010) "Inequality of Opportunity and Income Inequality in Nine Chinese Provinces, 1989-2006”, China Economic Review, 21(4): 607-616. 